\title{
Acumulação fictícia, especulação e instabilidade financeira. Parte I: uma reflexão sobre a financeirização a partir de Marx, Keynes e Minsky *
}

\author{
Ricardo Carneiro **
}

\begin{abstract}
Resumo
Este texto, tem como objetivo essencial, entender os principais traços da financeirização, à luz da contribuição de autores clássicos como Marx, Keynes e Minsky, dos quais se enfatiza algumas categorias analíticas, distintas, mas similares. Ao fazer isto, busca investigar como esses autores estabeleceram os fundamentos para o tratamento do tema, para a partir daí analisar as contribuições contemporâneas, abordadas em ensaio ulterior. Adota como perspectiva que o essencial é distinguir o conteúdo da forma, ou seja, o avanço geral do capital financeiro como etapa superior e desregulada do capitalismo, das formas concretas e históricas que este assume. No plano mais geral e abstrato, a financeirização representa a retomada e o aprofundamento da lógica patrimonial, fictícia ou especulativa de valorização do capital. Distingue-se da morfologia, que diz respeito aos agentes e mercados principais envolvidos nesse processo, e às suas relações.
\end{abstract}

Palavras-chave: Financeirização; Acumulação fictícia; Especulação; Instabilidade financeira; Crise financeira.

\section{Abstract \\ Fictitious accumulation, speculation and financial instability. Part I: conjectures on financialization based on Marx, Keynes and Minsky}

The essential objective of this text is to understand the main features of financialization in light of the contribution made by classical authors such as Marx, Keynes and Minsky, who emphasizes some peculiar analytical categories, both different and alike. In doing so, it seeks to investigate how these authors established the foundations to analyze the subject matter, and uses this approach to analyze the contemporary contributions, which will be addressed in a later essay. It surrounds the perspective that it is essential to distinguish the content from the form, i.e., the general progress of financial capital as the superior and unregulated stage of capitalism, from the concrete and historical forms that it assumes. On a more general and abstract level, financialization constitutes the resumption and deepening of the patrimonial, fictitious or speculative logic of capital accumulation. This latter level should be distinguished from that of morphology, related to the main agents and markets involved in this process, and to its relations.

Keywords: Financialization; Fictitious accumulation; Speculation; Financial instability; Financial crisis. JEL B500, B510, B140, B240, B260.

Este texto, dividido em duas partes, não tem a pretensão de realizar uma análise exaustiva e tampouco original da financeirização. Seu objetivo prioritário é o de entender os principais traços da dinâmica deste regime de acumulação de capital à luz de alguns autores clássicos como Marx e Keynes e Minsky, dos quais se enfatiza algumas categorias analíticas,

\footnotetext{
* Artigo recebido em 10 de janeiro de 2019 e aprovado em 13 de maio de 2019.

** Professor Titular do Instituto de Economia da Universidade Estadual de Campinas (Unicamp), Campinas, SP, Brasil. E-mail: carneirordm@gmail.com. ORCID: https://orcid.org/0000-0001-6623-684X.
} 
distintas, mas correlatas. Ao fazer isto, busca investigar como esses autores estabeleceram os fundamentos para o tratamento do tema. Na sua segunda parte, a ser publicada em um ensaio posterior, se tratará das contribuições contemporâneas.

A natureza e dinâmica dessa nova etapa do desenvolvimento capitalista, caracterizado pela ampla desregulação dos mercados, em particular o financeiro, vigente desde os anos 1980, após a derrocada do regime de capitalismo regulado ancorado nas instituições de Bretton Woods, têm sido objeto de reiteradas controvérsias, quanto ao seu significado e implicações tal qual mapeado nos trabalhos de Lapavitsas (2011) e Van der Zwan (2014).

Nas correntes contemporâneas, a dinâmica desta etapa do capitalismo é objeto de expressivas polêmicas. Há questionamentos, por exemplo, sobre o seu dinamismo produtivo e tecnológico comparativamente ao regime de Bretton Woods. Nesse campo, uma tese bastante disseminada é a da perda de dinamismo ou, pelo menos, a ampliação das assimetrias, ou seja, sua maior concentração setorial e geográfica. Faz parte das divergências, embora com mais consenso, os efeitos deletérios sobre a distribuição da renda e da riqueza e a precarização dos mercados de trabalho. Por fim, colocam-se as discordâncias no que tange à maior instabilidade e propensão às crises deste regime, sobretudo, mas não exclusivamente, na periferia do sistema.

Para analisar este conjunto de questões, este texto parte de algumas premissas gerais e de uma forma específica para abordá-las. Adota como perspectiva que o essencial é distinguir o conteúdo da forma, ou seja, o avanço geral do capital financeiro como etapa superior e desregulada do capitalismo, das formas concretas que este assume. No plano mais geral e abstrato, o processo observado após 1980, representa a retomada e o aprofundamento da lógica patrimonial, fictícia ou especulativa de valorização do capital, que havia sido abrandada pela regulação estatal dos mercados, em particular do financeiro, no âmbito do regime de Bretton Woods.

Quanto à morfologia, referente aos agentes e mercados principais envolvidos nesse processo, e às suas relações, postula-se a disseminação dessa lógica, de prevalência dos ganhos patrimoniais, fictícios, ou especulativos em todos os agentes econômicos: famílias, empresas não financeiras e empresas financeiras. Desta forma, no âmbito dos agentes se instala e desenvolve esta prática característica, que desta maneira reforça a sua reprodução no âmbito geral.

Como referido, para analisar as questões relativas à dinâmica desta fase do capitalismo, este texto está organizado em duas partes. Na primeira, realiza-se uma caracterização do conceito de acumulação fictícia, especulação e instabilidade financeira a partir de autores clássicos associados a estas categorias analíticas, respectivamente, Marx, Keynes e, Minsky.

Na segunda, a ser publicada em breve, a partir de um conjunto de autores que trataram da financeirização, examina-se a particular morfologia da dominância financeira no capitalismo contemporâneo destacando a forma de atuação dos principais atores econômicos, 
Acumulação fictícia, especulação e instabilidade financeira. Parte I: uma reflexão sobre a financeirização...

seus circuitos de valorização fictícia ou especulativos e os mecanismos que articulam a acumulação financeira à produtiva.

\section{Marx e a acumulação fictícia}

Um bom ponto de partida para a análise do capital portador de juros e sua forma desenvolvida, o capital fictício, é a consideração das formas ou dos elementos constitutivos do capital, tal qual apresentado em Carneiro et al (2015). No livro O Capital, Marx (2017, [1894]) apresenta as formas mais complexas ou desenvolvidas do capital, a partir dos desdobramentos das formas mais simples. Assim, numa sucessão que vai da Mercadoria ao Dinheiro, ao Capital em função, e ao Capital portador de juros e seu desdobramento, o capital Financeiro, chega-se pôr fim, à forma mais desenvolvida, o Capital Fictício.

Um aspecto crucial a ressaltar nesta abordagem é que as formas mais simples são superadas pelas mais complexas, mas o são de maneira dialética, no sentido em que são subordinadas por elas, mas não desaparecem, vale dizer, mesmo nas formas mais desenvolvidas e complexas, os elementos mais simples permanecem. Assim, por exemplo, um capitalismo desenvolvido, dominado pela acumulação fictícia pressupõe a produção de mercadorias, a existência do dinheiro, a acumulação produtiva, a mobilização de capital financeiro, porém todos subordinados aos seus ditames e ao mesmo tempo impondo-lhes os limites da sua existência.

Nos circuitos mais simples que vão da mercadoria ao dinheiro (M-D-M) e do dinheiro ao dinheiro (D-M-D), o principal aspecto a destacar é que a repetição e o desenvolvimento das trocas, ou seja, a reiteração da produção de mercadorias, leva necessariamente ao surgimento do dinheiro. O mais importante é que o dinheiro deixa de ser apenas um facilitador, um intermediário das trocas, para virar um objetivo em si mesmo. Ou seja, o segundo circuito desenvolve-se a partir do primeiro, mas passa a ser subordinado por ele: produz-se mercadorias para obter dinheiro e não outras mercadorias.

De uma forma direta, o dinheiro torna-se o objetivo último da troca porque ele é o representante geral ou equivalente geral das mercadorias. Representa, portanto, o meio de acesso ao mundo das mercadorias. Porém, exatamente por esta qualidade torna-se objeto de desejo e acumulação per se, vale dizer, sua circulação e acumulação deixam de estar referidos direta e imediatamente à circulação de mercadorias.

Numa frase magistral, no Capítulo 3 do Livro I de O Capital, Marx (loc. cit.) sintetiza o dinheiro e sua relação com o mundo das mercadorias: "Com a extensão da circulação de mercadorias cresce o poder do dinheiro, da forma sempre pronta, absolutamente social, da riqueza”. O dinheiro brota da existência e da circulação das mercadorias, porém se constitui numa forma superior da riqueza, com aceitação social imediata, que ao mesmo tempo representa e vai além do mundo das mercadorias. 
Na superação da mercadoria pelo dinheiro, aparece também a permanência da forma mercadoria e sua contradição com o dinheiro que se manifesta na dissociação entre as duas circulações. Isto decorre de dois aspectos principais: o primeiro, da forma do dinheiro como equivalente geral das mercadorias, conduzindo ao entesouramento, cujo efeito é a interrupção das trocas. O segundo, acarretado pela natureza do dinheiro como meio de pagamento, ou dinheiro creditício que permite que as mercadorias entrem em circulação sem o dinheiro, apenas contra promessas de pagamento.

A segunda passagem, ou terceiro circuito importante, é aquele que vai do dinheiro ao capital, expressa na circulação (D-M-D'), que é a fórmula do capital ou, mais precisamente, o capital em função. Como se pode observar, ela pressupõe tanto o dinheiro quanto as mercadorias, pois são formas que o capital necessariamente assume no seu processo de circulação. Mas, a existência de ambos está agora subordinada aos desideratos do capital, e à sua sede de valorização.

Tanto do ponto de vista lógico quanto histórico, a passagem do dinheiro e mais propriamente da moeda, - um artefato cuja origem se perde nas "brumas da história" como sugeriu Keynes (1935) - ao capital, supõe que ao final do processo este último se apresente acrescido, ante o montante inicial. Ou seja, ele supõe por sua vez, que o capital assume a forma particular de mercadorias e seja combinado com uma mercadoria singular, a força de trabalho para que daí resulte o excedente de valor ou a mais-valia.

Como se vê, o capital em função não tem uma forma própria, distinta da mercadoria e do dinheiro. Ele é sobretudo, uma relação social de produção, a qual supõe o trabalho assalariado, ou seja, não proprietários dos quais se extrai sobre trabalho. Por sua vez é também um processo, de valorização e a sua continuidade tem como suposto a concorrência, ou seja, outros proprietários de capital que buscam o mesmo fim. São esses dois vetores, o que contrapõe trabalho ao capital e aquele que opõe os capitais entre si, que asseguram o movimento de valorização e a obtenção de uma determinada taxa de lucro. Essa última depende, portanto, de variáveis objetivas como a taxa de exploração do trabalho ou a taxa de mais valia, o montante e composição do orgânica do capital, e a concorrência que se impõe de um modo imanente a todos os capitalistas.

Importante reafirmar que esse caráter mais abstrato do capital, vis a vis a mercadoria e ao dinheiro, cuja definição faz referência a um processo ou a uma função, não dispensa as formas mais elementares. O dinheiro não existe privadamente, tampouco as mercadorias, que constituem a substância do capital, ambos necessitando da validação social. Violar o processo (D-M-D'), ou seja, valorizar o capital sem que ele assuma essas formas, diz respeito a processos ou momentos muito particulares da história. Ou eles não se referem ao capitalismo já plenamente constituído, como por exemplo, a prática de acumular tesouros em metais preciosos ou riqueza enquanto estoques de mercadorias durante o mercantilismo. Ou se referem, como veremos, a formas superiores de acumulação de capital. 
Essa relação entre o capital em função e as suas formas necessárias podem ser ilustradas no próprio processo de valorização. Assim, a reprodução do capital exige a proporção correta entre os vários setores e em particular entre aqueles produtores de bens de consumo e meios de produção. Por sua vez, a insuficiência da demanda se traduz num excedente de mercadorias invendáveis ou força de trabalho desempregada. Por último, mas não menos relevante, escassez ou excesso de dinheiro, na forma de crédito, constituem fatos recorrentes nos ciclos de valorização. Assim, o capital, uma relação de produção mais desenvolvida, se submete à tirania das formas mais simples.

Em resumo, a forma particular do capital (D-M-D’) é o chamado capital em função ou em processo. Como assevera sua denominação, tem a sua existência associada aos processos concretos de produção e valorização. A sua remuneração é o lucro, obtido a partir de processos produtivos, os quais se apropriam de tecnologias determinadas e da força de trabalho, originando a mais-valia. Esses capitais são submetidos às leis imanentes da concorrência, cujo motor é a busca do lucro máximo. Nesse processo - cuja suposição é a mobilidade das várias frações do capital total, os capitais privados individuais - entre diferentes ramos produtivos, há subjacente ao processo, a persecução, jamais alcançada, do nivelamento da taxa de lucros.

Ao formular o conceito de capital portador de juros, Marx (2017, [1894]) distingue esta, que é a forma geral do capital (D-D'), da sua forma particular (D-M-D'). A primeira é uma relação de propriedade amparada numa estrutura jurídica, e formas variadas de contratos, por meio das quais o proprietário da mercadoria capital cede temporariamente seu valor de uso a terceiros. A forma por excelência da remuneração do capital propriedade é o juro, definido em cada momento do tempo de modo contingente, pela correlação de forças entre prestamistas e prestatários.

Um aspecto lógico-histórico de grande relevância a destacar é que o capital portador de juros, se origina da circulação do capital em função e depois se autonomiza. Assim, tanto nos ciclos de produção quanto nos de investimento, o capital assume formas materiais e formas líquidas (dinheiro). Nesta última forma, ele está temporariamente ocioso por conta do ciclo de produção e investimento e, portanto, disponível para ser emprestado. Com o desenvolvimento capitalista cresce esta massa de recursos ociosos que se torna um negócio de determinados capitalistas: banqueiros e distintos tipos de intermediários financeiros.

Esta dimensão do capital portador de juros, qual seja, a centralização de crescentes massas de capital líquido sob o controle monopolista de uma classe especial de capitalista, fossem eles bancos, financistas, capitalistas financeiros, etc., e seu comando sobre o capital produtivo, origina o conceito de capital financeiro e suas morfologias particulares e constituiuse no principal aspecto destacado pelas análises clássicas do tema, como por exemplo em Lenin (2012, [1917]), Hilferding (1985, [1910]) e Hobson (1985 [1906]).

Um aspecto tão ou mais importante do que este é menos destacado pela literatura marxista clássica, refere-se às implicações desta concentração e centralização do capitaldinheiro sobre a formação da remuneração singular do capital portador de juros: a taxa de juros. 
Como dimensão crucial deste processo, o capital a juros tem a sua remuneração estabelecida num processo político-jurídico, desconectado do processo produtivo. Há assim, um elemento crucial da formação da taxa de juros que deve ser resgatado e que se refere ao fato dela ser determinada na esfera da circulação do capital e não da produção, ou seja, a taxa de juros se forma de maneira independente da taxa de lucro.

Para Marx, com o desenvolvimento capitalista, o capital a juros converte-se na forma geral do capital. Ou seja, este último, que na sua origem era apenas uma cessão temporária e, portanto, uma duplicação ou espelho, na esfera jurídica ou contratual, do capital em processo, ganha autonomia. Isto porque com este desenvolvimento e ampliação da massa de riqueza financeira, a remuneração do capital em geral, o juro, se impõe como parâmetro geral de remuneração do capital, definindo o custo de oportunidade do capital sob a forma líquida ou a remuneração mínima das suas formas concretas de aplicação. A liquidez, a mobilidade, os usos alternativos desse capital e as relações contratuais que lhes são próprias sustentam a sua utilização como parâmetro. Ou seja, o juro passa a se constituir como a remuneração da forma mais geral do capital e, portanto, um padrão mínimo para as demais formas.

As relações entre as duas formas do capital - em função ou produtivo e a juros ou financeiro - são complexas e contraditórias. A forma mais geral e líquida, o capital a juros, seria num momento inicial de sua cessão, um espelho ou uma duplicação do capital em função. Há uma derivação teórica possível, que identifica o capital cedido em adiantamento no processo produtivo, como parte do capital em função e, portanto, com direito a uma alíquota da mais valia gerada no processo. Estariam assim delimitadas, por meio da especificação da remuneração, as relações entre as duas formas de capital e o limite ou teto que o lucro estabeleceria ao juro.

Contudo, o processo é muito mais complexo e contraditório. A consolidação do juro como padrão geral de remuneração do capital, e sua determinação de modo relativamente independente do lucro, sustenta a existência de divergência sistemática entre o valor do capital em função e do capital portador de juros. Isto porque como ressaltado corretamente por Lapavitsas (2009), ela dá origem a um processo crucial de cálculo do valor do capital por meio da capitalização. Esta consiste em tomar o fluxo futuro de rendimentos de um capital qualquer e trazê-lo a valor presente, utilizando a taxa de juros como parâmetro.

Imagine-se um valor inicial em capital dinheiro (D) convertido em capital em função (M), que retornará após certo lapso do tempo acrescido da mais valia (D'), ou seja, da taxa de lucro. Tome-se agora o mesmo valor adiantado sob a forma de capital a juros (D). Seus rendimentos prometidos ou esperados serão capitalizados a taxa de juros, gerando um valor adicional (D'). Há várias questões envolvidas nesses cálculos, mas a principal diz que os valores somente seriam coincidentes se a taxa de juros e de lucro fossem idênticas.

Há outro aspecto ainda mais relevante e que mostra a dominância do capital a juros ou financeiro. O próprio valor do capital em função passa a ser calculado pelo critério do capital financeiro. Ou seja, o que interessa é a capacidade real ou presumida de gerar rendimentos. A 
capitalização desses últimos define o valor do capital como um certo valor que, dada a taxa de juros, habilita o seu possuidor a obter estes rendimentos.

Um exemplo clássico desta dissociação foi elaborado por Hilferding (1985 [1910]), com o conceito de ganho de fundador. Assim, por exemplo, uma emissão de ações para ampliar o capital em função de uma empresa teria um valor de face correspondente ao adiantamento de capital. Mas, seu valor de mercado, ao qual poderia ser transacionado, seria distinto, correspondendo à capitalização dos rendimentos esperados. Esses rendimentos, representam um certo retorno ou rentabilidade de capital adiantado, e o primeiro só é adiantado porque dá direito a este fluxo de rendimentos. Aí vem a capitalização, que ocorre a uma outra taxa, a de juros, e gera um valor para o capital distinto do valor inicial ou de face.

Deduz-se da passagem acima, a forma mais abstrata do capital, o fictício, que corresponde à generalização do conceito de ganho de fundador de Hilferding. De um lado, o juro é remuneração do capital em geral, sendo passível de ser obtido por qualquer massa de riqueza líquida. Por outro, esta última passa a ter um valor fictício que depende, em cada momento do tempo, dos rendimentos esperados e da taxa de juros corrente à qual se realiza a capitalização. A rigor, como afirma Marx, qualquer forma de propriedade capaz de produzir um fluxo de renda apropriável privadamente, seja ela ou não produto do trabalho humano, como a terra, por exemplo, é capitalizada à taxa de juros corrente possuindo, portanto, um valor fictício enquanto capital.

A parte duplicada, o capital portador de juros, uma vez cedida ao capitalista produtivo, assume a forma de títulos ou direitos sobre a produção futura, com remuneração fixa (títulos de dívida), ou variável (ações). Em cada momento do tempo, o valor variável dessa massa de capital é calculado por meio da capitalização dos rendimentos à taxa de juros corrente. Esse valor nocional, por sua vez, ganha concretude quando da sua negociação nos mercados secundários. A existência desses últimos permite a concretização da divergência entre o valor original e o valor fictício do capital.

Assim, o capital fictício possui uma dinâmica própria que nasce da capitalização e se alimenta dos mercados secundários. Expectativas de variações dos rendimentos dos títulos de propriedade (ações), ou das taxas de juros correntes, são sancionadas por compra ou venda nos mercados secundários, ampliando ou reduzindo o valor fictício do capital. Essa trajetória assume caráter ampliado com a introdução do crédito, direcionado para compra dos títulos representativos do capital. Ou seja, os ciclos de preços desses ativos, na sua fase ascendente como demonstrado por Marx (loc. cit) nos capítulos finais da seção V do Livro III ou ainda por Hilferding (loc. cit.), ao analisar a operação da Bolsa de Valores - exigem a ampliação do crédito direcionado para esses mercados para dar liquidez ao valor ampliado dos títulos. As fases descendentes dos ciclos de preços, por sua vez, além de não conduzirem à realização dos ganhos esperados, geram um espectro de dívidas não pagas.

Os ciclos de flutuação de preços do capital portador de juros e das suas formas, definem um campo particular de acumulação de capital, a acumulação fictícia de capital, que a rigor 
constitui a esfera mais relevante da determinação da dinâmica capitalista. A sua intensificação gera mecanismos importantes de alavancagem e de relativo descolamento das outras formas de acumulação. O crédito e contemporaneamente, os derivativos, são os dois principais instrumentos de ampliação da elasticidade dos processos fictícios de valorização.

É importante destacar o papel importante atribuído ao crédito na acumulação fictícia por esses autores, mas ao mesmo tempo mais limitado do que aquele que lhes é atribuído por autores contemporâneos. Ou seja, a criação ex nihilo de poder de compra por parte dos bancos, não é um conceito amplamente usado por Marx (op. cit) ou Hilferding (op.cit) que utilizam preferencialmente a ideia de intermediação de recursos monetários ou capital, ociosos. Marx certamente não considerou o crédito nas suas manifestações mais desenvolvidas, por conta de um condicionante histórico, qual seja, o estágio do desenvolvimento bancário na sua época. Já Hilferding estava mais interessado na centralização do capital e seu controle por parte dos bancos.

Os derivativos não foram abordados por Marx. Mas a sua relevância contemporânea nos processos de valorização fictícia torna-os um instrumento central. Assim, há uma distinção entre os mercados à vista, e os mercados futuros e de outros derivativos. Os primeiros realizam a valorização ou desvalorização fictícia do capital. Já nos mercados de derivativos, essas flutuações são garantidas, ampliadas ou reduzidas. Outra diferença importante é que no mercado de derivativos a valorização prescinde da posse do ativo, ou seja, compra-se e vendese apenas a variação de preços ou de valor dos ativos subjacentes. Por fim, e o mais importante, como ressaltado por Palludeto (2017), o mercado de derivativos realiza a completa comoditização dos riscos, vale dizer sua completa intercambiabilidade, resultante da sua unificação e comparabilidade. A abstração das formas concretas atinge o seu paroxismo.

Com essas características e instrumentos, como veremos na segunda parte deste ensaio, na economia contemporânea, a acumulação fictícia ganha muita elasticidade e descola-se de maneira significativa da acumulação produtiva e mesmo da financeira. Mas não de forma absoluta. A capitalização ocorre a partir de uma taxa de juros geral e de um fluxo de rendimentos esperados de um ativo qualquer e que se baseiam em expectativas. Assim, tanto a forma de calcular o valor do capital, quanto seu caráter expectacional, já introduzem um elemento de arbitrariedade ou, pelo menos, de convenção neste cálculo. Isto é muito potenciado nos mercados secundários alavancados pelo crédito e ainda mais no mercado de derivativos. Mas, há um limite - impossível de delimitar a priori - que não se pode romper. Do mesmo modo que o dinheiro é abstrato, a forma geral da riqueza, mas não pode prescindir das mercadorias, a acumulação fictícia não pode, tout court, prescindir da acumulação produtiva.

\section{Keynes e a especulação}

Embora o tema do capital fictício e da sua acumulação não seja tratado explicitamente e com esta terminologia na obra de Keynes, é exatamente deste assunto que ela trata de modo substantivo. Tanto quando aborda o funcionamento de uma economia capitalista, quanto ao seu 
resultado, a problemática da teoria keynesiana se assemelha à da marxista, embora as prescrições de medidas para superar o que entende como os problemas do capitalismo - tais como a concentração da renda e da riqueza e a elevada instabilidade e propensão ao desemprego - divirjam profundamente.

É comum que nas correntes teóricas derivadas da obra de Keynes se considere como principal aspecto de seu trabalho, sobretudo da Teoria Geral, a questão da insuficiência da demanda efetiva e a propensão crônica ao desemprego na economia capitalista. Embora esta linha de interpretação esteja correta, ela perde o foco sobre as razões desta insuficiência bem como dos remédios para saná-la. Em outras palavras, na economia monetária da produção, que é o objeto central de análise da obra de Keynes, as flutuações, a insuficiência da demanda efetiva e a propensão permanente ao desemprego, derivam da especulação na circulação financeira. Esta última é inerente ao sistema capitalista e os remédios para lidar com as suas consequências não estariam prioritariamente, no ativismo da política macroeconômica, físcal ou monetária, mas no aprofundamento da regulação estatal e na limitação do poder dos rentistas.

A despeito das divergências com a teoria marxista, há pelos menos três aspectos nos quais o marxismo e o keynesianismo se aproximam: na análise do dinheiro e da sua centralidade; na determinação, como categorias independentes, da taxa de lucros (Eficiência marginal do capital) e das taxas de juros; e na centralidade dos mercados financeiros e da especulação, enquanto sinônimo da acumulação fictícia, como elementos intrínsecos da dinâmica capitalista.

A importância e especificidade do dinheiro aparecem em várias passagens da Teoria Geral, em particular no Livro IV. Assim, por exemplo, no capítulo 17, ao discutir a centralidade da taxa monetária de juros, Keynes (1992, [1936]) chama a atenção para as duas especificidades da moeda comparativamente às demais mercadorias: elasticidades de produção e substituição iguais a zero. A primeira propriedade, significa que a moeda não pode ser produzida diretamente pelo setor privado não bancário e tampouco a elevação do seu preço permite que se aumente diretamente a sua produção. Em outras palavras, a variação da quantidade de moeda é um processo que necessita de validação social. Isto vale mesmo para os bancos, cuja propriedade de criação monetária deriva da prerrogativa cartalista que lhes é transferida parcialmente pelo Estado, a quem cabe em última instância sancionar a criação de moeda bancária.

A questão enunciada acima é de grande relevância pois coloca a validação social como um momento importante da criação monetária. Claro, isto vale para qualquer mercadoria que só realiza seu valor se encontra mercado e se converte em moeda. Porém, no caso da moeda, esta restrição se põe de forma imediata para os produtores de mercadorias, mas também de forma mediata para os criadores de moeda - bancos e autoridade monetária. Ou seja, a moeda criada por ambos está sujeita à validação social como, por exemplo, quando a autoridade monetária cria mais moeda e esse adicional é "entesourado". Ou quando os bancos a despeito 
de mais líquidos decidem não fazer empréstimos adicionais. Ou quando não há demanda para empréstimos adicionais.

A outra propriedade da moeda é a elasticidade de substituição nula significando que, como a moeda não tem valor de uso intrínseco, mas apenas valor de troca, quando o seu valor aumenta não há incentivo para trocá-la por outros bens. Ou seja, ela representa uma quantidade determinada de todos os outros bens, e de suas combinações e, portanto, um repertório de amplas possibilidades, presentes e futuras. Dito de outra forma, converter a moeda em bens permite apropriar uma parte dos mesmos com a renúncia de incontáveis possibilidades.

$\mathrm{Na}$ verdade, nesta passagem, Keynes está discutindo por que o retorno da moeda, ou seja, a taxa monetária de juros, é mais rígida do que a dos outros bens e, no fundo, a razão crucial é porque a moeda é uma reserva de valor por excelência, uma ponte para o futuro, ao contrário dos outros bens que além de conversão incerta em dinheiro, tem custo de manutenção.

Com estas características das elasticidades de produção e substituição nulas, a moeda se converte numa unidade de conta que denomina salários, contratos e dívidas. Ou seja, as duas características devem ser sistematicamente respeitadas para assegurar a aceitação da moeda enquanto tal. Assim, mesmo em regimes de dinheiro puramente fiduciário nos quais a criação de moeda é prerrogativa dos bancos centrais e dos bancos privados, essas propriedades não podem ser violadas, sob pena de desencadearem um processo de rejeição monetária. Vale dizer, produzir moeda, descolada da sua validação social, ou introduzir um custo de manutenção, sob a forma de inflação, pode colocar em xeque a existência de um padrão monetário estável. Para entender esta restrição é necessário analisar um outro lado do problema: o da demanda por moeda e suas formas.

A análise da demanda por moeda da Teoria Geral se inspira na formulação inicial do Treatise on Money, (Keynes, 1930) que distingue uma demanda de moeda para transações reais (circulação industrial) e outra para a riqueza (circulação financeira). Na Teoria Geral, Keynes desdobra a demanda para transações no motivo transação e no motivo precaução. Introduz mais claramente o motivo especulativo que também denomina de demanda especulativa. Enquanto os dois primeiros guardam relação com a renda, o segundo está associado à riqueza e a uma característica especial da moeda enquanto tal: a preferência pela liquidez, significando esta última, a preferência por deter riqueza na sua forma monetária e, portanto, líquida.

O conceito de preferência pela liquidez ressalta o caráter de riqueza involucrado na moeda. Aqui, o importante, para os detentores de riqueza, é a escolha entre moeda e outras formas de riqueza mobiliária, ou seja, títulos. Não está colocada, exceto em momentos de ruptura do padrão monetário, a opção entre moeda e ativos reais. Assim, pergunta Keynes, por que alguém escolheria manter a riqueza em sua forma líquida sem receber rendimentos, quando tem a alternativa de possuir títulos e auferi-los? A resposta óbvia é a flexibilidade permitida pela forma líquida da riqueza e a expectativa quanto à alteração dos rendimentos, ou seja, quanto às taxas de juros. 
Aquele possuidor de riqueza que acredita na subida das taxas de juros - e queda dos preços dos títulos - o baixista, tende a permanecer na moeda. Já aquele que aposta na queda das taxas de juros - e aumento dos preços dos títulos - o altista, compra títulos. Esta interação de baixistas e altistas conforma a curva de preferência pela liquidez, com o predomínio de uma ou outra posição e tem formato bastante variável ao longo do tempo. Nesse caso, é muito importante não somente o predomínio de uma ou outra posição, como também o grau de polarização e a intensidade da mesma.

O raciocínio inicial de Keynes, na determinação da taxa de juros, considera uma oferta fixa de moeda, a distribuição da demanda entre transação + precaução e a demanda especulativa e relacionada a esta última, uma curva de preferência pela liquidez. Nessas circunstâncias, deslocamentos desta curva fazem variar a taxa de juros. Claro que há alterações exógenas (via Banco Central) e endógenas (via bancos) da oferta de moeda, mas raciocinar com a quantidade de moeda fixa, é importante para assinalar a relevância que tem na determinação das taxas de juros, a forma pela qual os agentes privados decidem manter a sua riqueza.

Introduzir a variação na oferta de moeda - exógena ou endógena - muda parcialmente os termos de determinação da taxa de juros. Assim, coeteris paribus, dada uma convenção qualquer, i.e. um formato da curva de preferência pela liquidez, uma ampliação da oferta de moeda fará reduzir a taxa de juros. Mas, esta é apenas uma possibilidade que ocorre quando as posições baixistas e altistas não estão polarizadas. Pode ocorrer também um deslocamento simultâneo da curva de preferência pela liquidez, deixando a taxa de juros inalterada ou mesmo ocasionando a sua subida.

O que se destaca no raciocínio anterior é que a taxa de juros é determinada pela interação entre os criadores de moeda - banco central e bancos - e os agentes privados detentores de riqueza e a composição de seu portfólio. Importante também assinalar que nesta interação entre criadores e demandantes de moeda, Keynes se refere à taxa de juros de curto prazo. De fato, nesse caso, a Autoridade Monetária ao injetar moeda comprando títulos de curto prazo de propriedade dos bancos tem um poder quase unilateral na fixação dessas taxas. A questão maior, contudo, é que existe um espectro ou uma curva de juros com títulos públicos e privados de diversos prazos. A passagem de curto para o longo prazo é o resultado da ação dos agentes privados detentores de riqueza e de suas preferências. Por isso, Keynes se refere com grande ênfase ao fato de que a tarefa da política monetária é não somente alterar a taxa de juros de curto prazo, mas induzir os agentes privados a alterar as taxas longas, por meio da alteração das suas expectativas.

Nas suas reflexões sobre os determinantes da taxa de juros, Keynes desenvolve ainda o conceito de preferência absoluta pela liquidez, ou numa denominação mais inapropriada, armadilha da liquidez. Ela ocorreria em situações de polarização radical de posições, vale dizer de predomínio acentuado das posturas baixistas. Assim, se há uma forte e intensa expectativa de que as taxas de juros subirão no futuro, a ampliação da oferta monetária terá pouca influência nas mudanças das taxas de juros correntes. Ou, dito de outra maneira, a ampliação da oferta de 
moeda não induzirá os agentes privados a se desprenderem da liquidez, porque creem que poderão fazê-lo em melhores condições, no futuro.

Nessa análise da determinação das taxas de juros, Keynes descarta inteiramente a ideia de que a taxa de juros tenha como determinante a oferta (poupança) e demanda de fundos para investimento. No que diz respeito à interação entre a oferta e demanda de fundos, para ele, o essencial para a determinação das taxas de juros é a forma pela qual os detentores de poupança decidem mantê-la, sob a forma mais ou menos líquida. Ademais, o relevante não é o fluxo de poupança ou o que não foi consumido da renda num determinado período, mas o seu estoque, ou seja, a poupança financeira, ou estoque de capital fictício, diria Marx, acumulado ao longo do tempo.

Assim, a demanda por fundos para investimento não interfere na determinação das taxas monetárias de juro. Uma vez determinadas estas últimas, de acordo com os elementos expostos acima, a demanda por fundos, ou o fluxo adicional de financiamento que depende da lucratividade ou da eficiência marginal do capital (EMGk), será satisfeita por meio da interação entre o finance ou financiamento de curto prazo e o funding, que é a sua consolidação em dívida bancária ou títulos longos de dívida direta. Mais do que a interação entre o os fluxos adicionais de demanda e oferta de fundos para investimento, são as arbitragens ao longo das curvas de juros envolvendo todo o estoque de poupança financeira segundo prazos e risco, e não as relações entre fluxos, que resultam na determinação das taxas de juros. O ponto mais importante a assinalar é que a taxa de juros está determinada num plano inteiramente distinto do retorno do investimento, ou da Emgk. Desse ponto de vista, a abordagem de Keynes, a despeito das categorias distintas, é muito semelhante à de Marx. Vejamos, pois, a discussão quanto à Emgk.

Na construção do conceito de Emgk, entram dois elementos: a série de rendimentos esperadas do ativo instrumental, ao longo da sua vida útil, e o preço de oferta ou custo de produção/reposição. A EMgk é uma taxa de retorno calculada como uma taxa de desconto que igualaria o valor presente do fluxo de rendimentos do ativo instrumental ao seu preço de oferta. Pode ser dito de outra forma: a EMgk seria a taxa de desconto que iguala o preço de demanda - valor presente da série de rendimentos - ao preço de oferta.

Duas observações importantes sobre o que está dito acima: a EMgk é uma taxa de retorno própria dos ativos instrumentais que será comparada com o retorno da moeda, a taxa monetária de juros, nas maturidades compatíveis, para a decisão de investimento. A sua determinação é inteiramente independente da taxa de juros, sendo resultado de variáveis tecnológicas e expectacionais.

O raciocínio de Keynes é similar ao de Marx: a taxa de retorno sobre a moeda, que é a forma líquida da riqueza, é o parâmetro geral ou o piso para o retorno dos demais ativos. Em princípio, qualquer ativo cujo retorno estivesse abaixo da taxa de juros, não seria demandado. Ou seja, não faria sentido investir num ativo menos líquido cuja taxa de retorno fosse inferior à do ativo líquido. Por esta definição, tal qual em Marx, a taxa monetária de juros é um custo 
Acumulação fictícia, especulação e instabilidade financeira. Parte I: uma reflexão sobre a financeirização...

de oportunidade genérico, ao qual toda decisão de aquisição de ativos é referida. A afirmação, por sua vez, deve ser entendida no seu sentido macroeconômico, ou seja, não se trata de construir uma teoria da decisão de alocação de portfólios individuais, nas quais variáveis específicas tem um peso importante, mas de enfatizar os parâmetros gerais que condicionam a alocação desses portfólios.

Voltando a EMgk, Keynes dá grande destaque a fatores objetivos e subjetivos, como as expectativas. Neste último caso, variáveis reais como alteração de preços relativos e dos rendimentos, mudanças nos custos de produção de equipamentos similares e até mesmo variações das taxas de juros de curto prazo, com impacto nos custos, são essenciais. Do ponto de vista objetivo e como tendência geral, ressalta a escassez ou o seu contrário, a abundância dos ativos instrumentais, na medida em que reduzem os rendimentos e aumentam os preços de oferta, com fator de queda da EMgk.

Esses dois parâmetros, a taxa monetária de juros, ou melhor, o espectro das taxas de juros e a EMgk, determinados de maneira independente, são cruciais para a visão de Keynes da dinâmica capitalista e do que era a sua preocupação central à época que escreveu a Teoria Geral, a tendência inerente ao desemprego e a subutilização do potencial de crescimento em geral. Todavia, essa análise da dinâmica só se pode dar no contexto da existência de mercados organizados - de títulos e de propriedade - para a negociação dessas várias formas de riqueza. $\mathrm{O}$ crescimento e a liquidez desses mercados introduzem uma escolha crucial e que vai além daquela expressa pela dicotomia taxa de juros x EMgk e que diz respeito à escolha entre riqueza nova e riqueza velha. Com este passo, Keynes postula o tema da acumulação fictícia embora não utilize este conceito, mas o de especulação.

Várias passagens na Teoria Geral ilustram o uso implícito do conceito da acumulação de capital fictício. Por exemplo, no capítulo 16 ao fazer a distinção entre o ato de poupar e o de investir, negando a passagem automática de um ao outro, Keynes afirma: "Além disso, para que um indivíduo que poupa possa atingir o seu fim, que é o de adquirir riqueza, não é necessário que um novo bem de capital seja produzido para satisfazê-lo... Cada ato de poupança implica transferência forçada inevitável de riqueza a quem poupa, embora este, por sua vez, possa sofrer as consequências da poupança dos outros. Essas transferências de riqueza não requerem a criação de riqueza nova - na realidade, como vimos, podem ser ativamente antagônicas" (p. 168).

Nesta passagem, Keynes está discutindo a necessidade de que a taxa de juros seja inferior à EMgk para que haja criação de nova riqueza. Mas, o fato é que isto pode não ocorrer. E se não ocorrer, o fluxo de poupança nova será direcionado para a moeda, ou títulos que representam riqueza já criada. E este processo pode não estar sujeito à autocorreção que viria da aquisição de títulos da riqueza velha, aumento dos seus preços e redução dos juros. Tudo dependerá de qual seja o comportamento da preferência pela liquidez. Desta forma uma certa configuração entre taxa de juros e preferência pela liquidez pode dirigir os fluxos de poupança 
de maneira recorrente para a acumulação fictícia ou revalorização da riqueza velha, ou seja, para a especulação, sem impacto na renda.

Esta possibilidade de acumulação de riqueza fictícia, tratada no plano dos fluxos de nova poupança pode, todavia, condicionar os movimentos do estoque de riqueza. Eis o que diz Keynes (1992, [1936]) no capítulo 12, ao discutir a lógica de operação mercados financeiros: "Se me é permitido aplicar o termo especulação à atividade que consiste em prever a psicologia do mercado e o termo empreendimento à que consiste em prever a renda provável dos bens durante toda a sua existência, de modo algum se pode dizer que a especulação sempre prevaleça sobre o empreendimento. À medida em que progride a organização dos mercados de investimento, o risco de um predomínio da especulação, entretanto, aumenta" (p. 131).

Na passagem acima estão colocados todos os elementos da acumulação fictícia, exceto um deles que talvez fosse óbvio demais para o autor. De um lado, a organização dos mercados e sua crescente liquidez. De outro, a prevalência da lógica especulativa dos ganhos patrimoniais em detrimento da lógica do empreendimento ou dos ganhos com rendimentos. O elemento faltante é o crédito que confere elasticidade ao processo e cuja importância foi relevada por Keynes na Teoria Geral, de forma distinta ao que tinha feito no Treatise on Money (1930). Ou seja, caso o crédito não financiasse a especulação, a acumulação fictícia dependeria dos fluxos periódicos de nova poupança para sustentar processos de valorização. $\mathrm{O}$ crédito, enquanto criação ex-nihilo de poder de compra, liberta tanto o investimento instrumental quanto a especulação das amarras da poupança.

A ausência do crédito, ou da moeda endógena criada pelos bancos, na Teoria Geral, certamente torna menos nítidos os elos assinalados acima, entre liquidez, mercados financeiros e especulação. Também contribui para interpretações simplificadas do funcionamento do capitalismo, ao suprimir não só a criação de crédito, mas a crucial interação dos bancos no processo de financiamento da acumulação de ativos. Este é um tema muito trabalhado por Minsky, como veremos a seguir.

\section{Minsky e a instabilidade financeira}

A questão do crédito e dos bancos, posta em segundo plano por Keynes na Teoria Geral, é o tema central do qual parte Minsky $(1977,1992,1993)$, na sua reinterpretação deste autor, por meio da construção do paradigma da instabilidade financeira. Enfocando a obra de Keynes desta maneira, Minsky (loc. cit.), põe ênfase na instabilidade intrínseca do sistema capitalista e na sua propensão às crises financeiras. Assim, destaca as relações financeiras, sua interação com variáveis reais e a sua centralidade na dinâmica capitalista.

Embora um autor keynesiano na sua essência, cabe referir Schumpeter, como outra filiação teórica importante de Minsky (1988), e que aparece no caráter crucial que atribui ao crédito na hipótese da instabilidade financeira. Para ilustrarmos este ponto, cabe destacar a seguinte ideia de Schumpeter (1982 [1934]): o crédito é essencialmente a criação de poder de compra com o propósito de transferi-lo ao empresário, mas não simplesmente a transferência 
de poder de compra existente. A criação de poder de compra caracteriza em princípio, o método pelo qual o desenvolvimento é levado a cabo num sistema com propriedade privada e divisão do trabalho. Através do crédito os empresários obtêm acesso a corrente social dos bens antes que tenham adquirido o direito normal a ela. Ele substitui temporariamente, por assim dizer, o próprio direito por uma ficção deste (p. 74).

Assim, partindo da ideia chave de que o Investimento em ativos instrumentais, ou seja, o investimento produtivo, é a variável crucial que define a dinâmica da economia capitalista, Minsky $(1977,1992,1993)$, postula que a decisão de investir é necessariamente intermediada pelos mercados financeiros que distorcem e modificam os parâmetros para esta decisão. Ou seja, a decisão de investimento significa escolher entre a compra e posse de ativos e numa economia capitalista supõe necessariamente o acesso ao crédito, tornando o financiamento uma parte crucial do processo.

Introduzir o financiamento na decisão de investir implica em dar destaque a um elemento crucial, qual seja, o espectro de taxas de juros segundo seus prazos e riscos. Seguindo Keynes, Minsky (loc cit) afirma que a decisão de investimento depende da relação entre preços de ativos financeiros e preços da produção corrente. Na verdade, se refere aos preços dos ativos instrumentais avaliados ou precificados pelos mercados financeiros e o preço ou custo de produção do mesmo ativo instrumental.

Nesta avaliação, o espectro de taxas de juros desempenha papel crucial: a taxa de juros longa, na precificação do ativo instrumental enquanto ativo financeiro, o que se daria pela capitalização dos rendimentos e mais especificamente dos dividendos. A taxa de juros curta, por sua vez, seria um dos elementos importantes na definição do preço corrente do ativo instrumental ao impactar os custos de produção. Assim, a curva de juros, vale dizer, a sua inclinação, ou ainda a relação entre taxas longas e curtas jogaria um peso crucial na decisão de investimento. Suas modificações exógenas, para além dos elementos particulares desta decisão relativos aos fluxos de caixa, teriam um peso crucial na trajetória do investimento.

Dados os preços relativos, no caso, a relação entre preços financeiros e preços correntes dos ativos instrumentais e as expectativas sobre o comportamento futuro dessa relação, a decisão de investimento é condicionada à disponibilidade de financiamento. Ou seja, para realizar seus investimentos, cujo montante vai além das disponibilidades imediatas, os capitalistas necessitam de crédito e acessam esses recursos via contratos onde trocam dinheiro hoje, por dinheiro futuro ou promessas de pagamento.

Independentemente da forma desses contratos, a sua validação depende essencialmente dos fluxos de caixa resultantes do investimento. Ou seja, a validação dos débitos supõe que os fluxos de caixa oriundos do investimento superem os custos de produção. Há aqui, portanto, um terceiro elemento a considerar: o custo do financiamento. A primeira decisão é tomada comparando-se o preço demanda do ativo; que é igual ao fluxo de rendimentos esperados capitalizado à taxa de juros corrente de longo prazo; ao preço de oferta; que é igual ao custo de produção de um novo bem de capital; o qual computa a taxa de juros de curto prazo. 
Isto posto, há que considerar o custo de financiamento, na verdade, a repartição do fluxo de caixa deduzido impostos e depreciação, entre pagamento dos contratos de dívida e o lucro do empresário, lembrando que é este último cuja capitalização define o preço de demanda - ou seja, a capitalização do fluxo de caixa livre para pagamento de dividendos. Por este enunciado percebe-se que para além das expectativas quanto à trajetória da economia, as condições financeiras, i.e., as curvas de juros e as condições de financiamento são os determinantes cruciais da decisão de investimento.

No que se refere à geração de fluxos de caixa, Minsky adota a postulação da macroeconomia keynesiana desenvolvida por Kalecki (1977), a partir dos esquemas de reprodução de Marx, qual seja, a de que o novo investimento é o mecanismo central de validação dos investimentos antigos, ou seja, o investimento é o gasto central que gera os lucros e via o multiplicador, a renda. Por simplificação, Minsky exclui o outro componente autônomo do gasto, o consumo dos capitalistas, que tem do ponto de vista da autonomia o mesmo estatuto do investimento, pois ambos supõem o acesso ao crédito que os liberta dos lucros acumulados ou da poupança prévia.

Há uma justificativa para a escolha de Minsky e que se refere ao caráter mais decisivo do investimento vis a vis o consumo capitalista na configuração do ciclo. Isto se prende não só aos determinantes distintos e à natureza dos gastos - empresariais versus pessoais - mas à dupla natureza do investimento que é ao mesmo tempo ampliação da demanda efetiva e da capacidade de produção e que conduz, à medida em que avança, à ociosidade da estrutura produtiva e redução da taxa de lucro corrente. O próprio Kalecki (1977), ao discutir as visões antagônicas sobre o problema da sustentação da taxa de acumulação, já havia alertado para este aspecto ao discutir os limites do crescimento fundado no investimento e sua desaceleração inexorável.

Isto posto, se a problemática de Minsky se reduzisse à validação do investimento por meio da chamada equação dos lucros kaleckiana, sua contribuição seria lateral, pois como assinalado, o próprio Kalecki já havia demonstrado a inevitabilidade do ciclo e, portanto, a insuficiente validação do investimento que decorreria de sua reversão inexorável, a partir da ampliação da ociosidade e queda da lucratividade corrente. Todavia, a contribuição de Minsky é original, ao introduzir a mediação e centralidade das finanças. Isto torna o sistema não somente cíclico, mas instável e propenso às crises.

Ao introduzir na análise kaleckiana do ciclo as condições de financiamento, Minsky (1977, 1992, 1993), propõe a hipótese da instabilidade financeira. Esta diz respeito à fragilidade criada por duas características inerentes do funcionamento do capitalismo: o aumento da alavancagem no financiamento da aquisição dos ativos e o crescente descasamento de prazos e taxas (mismatch) entre posições ativas e passivas. Ao fazer isto, o autor enfatiza o caráter míope e mimético do mercado na avaliação das condições econômicas e destaca a natureza pró-cíclica intrínseca do crédito e o relaxamento das margens de segurança. 
Acumulação fictícia, especulação e instabilidade financeira. Parte I: uma reflexão sobre a financeirização...

As condições iniciais do ciclo mediado pelas finanças tendem a se alterar rapidamente. Assim, dado um investimento inicial financiado por uma determinada relação recursos próprios/recursos de terceiros (alavancagem), e relação entre juros curtos e longos (curva de juros) e estrutura de balanço (descasamento), seu sucesso ou validação, por período de tempo relevante, induz tanto os empresários quanto os seus financiadores, bancos e intermediários financeiros, a intensificar a alavancagem e eventualmente o descasamento.

$\mathrm{Na}$ trajetória de crescente alavancagem e descasamento, surgem várias dimensões da fragilidade. Mesmo que nada ocorra com os parâmetros relativos ao financiamento, ou seja, que não haja alteração nas condições financeiras, i. e. com as taxas de juros, diante da crescente alavancagem a desaceleração inerente do ciclo real, implicará crise financeira. Isto porque, como já apontado, a redução do investimento decorrente da redução da lucratividade corrente, implicará na não validação das estruturas financeiras construídas na etapa de expansão.

Mesmo no ciclo dominado por variáveis reais, ou seja, pela desaceleração no crescimento dos fluxos de caixa, já existe a possibilidade de interferência das variáveis financeiras condicionando a intensidade e duração da reversão. Por exemplo, pode-se supor que diante de lucros menores, os empresários optem por pagar suas dívidas e com os fluxos de rendimentos reduzidos obtenham um preço de demanda por ativos instrumentais inferiores. Dado que os preços de oferta não se alteraram, isto motivaria uma redução ulterior do investimento, dos fluxos de caixa e da validação das dívidas. Outra possibilidade é que estes empresários, em concordância com o sistema financeiro, resolvam refinanciar parte das dívidas na tentativa de manter o preço de demanda e consequentemente o investimento. Quando a desaceleração do ciclo se materializar, isto produzirá um desequilíbrio mais severo, decorrente do aumento da alavancagem.

As mudanças mais intensas e inevitáveis, advêm, todavia, das alterações nas condições de financiamento, i.e., das mudanças dos juros acompanhadas ou não da inclinação da sua curva. Mas, antes mesmo que isto ocorra é possível, mas improvável, que os financiadores bancos e intermediários - diante do aumento da alavancagem própria do ciclo, resolvam ampliar o custo do crédito, com ou sem racionamento. Os efeitos são semelhantes aos apontados acima - redução do preço de oferta e ulterior contração do investimento e maior fragilidade financeira, no caso do refinanciamento.

Quando se alteram as taxas, curva de juros e condições de financiamento, surgem várias combinações possíveis para o aprofundamento da fragilidade financeira e sua transformação em crise. Assim, uma elevação da taxa longa implicará numa redução do preço de demanda do ativo. O mesmo efeito ocorrerá com um aumento da taxa de juros do crédito, se os agentes decidem não ampliar a alavancagem. Por fim, aumento das taxas curtas ampliam o preço de oferta do ativo. A combinação entre as variações dessas taxas definirá o impacto sobre o investimento, os lucros e a validação dos financiamentos. Certamente, quanto mais intenso e simultâneo o movimento das taxas, maior o seu impacto no investimento corrente e na intensidade da crise financeira. 
Assim, para Minsky (loc. cit.), o problema central seria a alavancagem que promoveria um crescente descolamento entre rendimentos que dependem do mercado de bens e obrigações e valores determinados pelos mercados financeiros. Além disto, o descasamento (mismatch) e as estruturas de financiamento muito assincrônicas, também podem jogar um papel decisivo no aprofundamento da crise ao ampliar os encargos financeiros com amortizações não refinanciadas.

É conhecida a tipologia com a qual Minsky classificou as unidades empresariais e a sua vulnerabilidade diante das mudanças nos ciclos, nas taxas de juros e nas condições de financiamento. É importante discutir o seu significado, levando em conta tanto a dimensão corrente quanto a patrimonial, pois ele define tanto a resistência às crises financeiras quanto a profundidade das mesmas. Diante de mudanças no conjunto de variáveis indicadas acima, as unidades hedge teriam fluxos de caixa suficientes para cobrir as obrigações financeiras. Por sua vez, o valor dos ativos, marcados a mercado, superaria o das dívidas, resultando em patrimônio líquido positivo.

As empresas especulativas não teriam cobertura de fluxo de caixa suficiente para os encargos, apresentando um desequilíbrio corrente, mas este desequilíbrio seria temporário porque o valor presente do fluxo de caixa esperado seria superior ao valor descontado das obrigações. A precificação de ativos e passivos ainda redundaria em um patrimônio líquido positivo. Por fim, teríamos as unidades Ponzi, nas quais os fluxos de caixa seriam insuficientes para fazer frente aos encargos das dívidas obrigando ao endividamento adicional. A avaliação dos ativos e passivos indicaria o maior montante desses últimos resultando em patrimônio líquido negativo.

Com a tipologia descrita acima, Minsky (loc. cit.) procurou indicar o grau de fragilidade das empresas às mudanças inerentes ao ciclo econômico-financeiro. Mais que isto, pela própria natureza pró-cíclica da oferta e demanda de crédito, concluiu pela necessária redução das margens de segurança das empresas e seu deslocamento para posições mais frágeis. Assim, os estágios do ciclo estão associados à predominância dos tipos de empresas sendo caracterizados pelo deslocamento, das posturas hedge para especulativa e finalmente, Ponzi. É crucial assinalar a natureza financeira ou de balanço, do desequilíbrio decorrente da crise financeira, cuja solução supõe não apenas a retomada dos fluxos de caixa, mas um reequilíbrio da situação patrimonial.

A contribuição de Minsky, ao resgatar o crédito e as finanças e associá-los ao ciclo, demostrando a partir daí o primado e a inevitabilidade das crises financeiras, foi crucial. Contudo, deve-se assinalar que, se a sua abordagem representa um passo à frente numa lacuna deixada por Keynes na Teoria Geral, na qual o crédito é considerado apenas lateralmente, constitui também um passo atrás, na medida em que trata em segundo plano o conceito de especulação. Toda a hipótese da fragilidade financeira é construída a partir de um esquema analítico que considera apenas a acumulação de ativos instrumentais. Esta perspectiva teórica reflete, sem dúvida, o período histórico no qual o autor formulou as suas interpretações, 
Acumulação fictícia, especulação e instabilidade financeira. Parte I: uma reflexão sobre a financeirização...

marcado por uma forte regulação do capitalismo, mormente dos mercados financeiros. Todavia, a sua abordagem é o suficientemente abrangente para incorporar a introdução das possibilidades de escolha entre riqueza nova (ativos instrumentais) e riqueza velha (ativos financeiros nos mercados secundários), lançando luzes sobre dimensões adicionais da instabilidade e da crise financeira.

\section{Referências bibliográficas}

CARNEIRO, R.; ROSSI, P.; MELLO, G.S.; CHILIATTO-LEITE, M.V. The fourth dimension: derivatives and financial dominance. Review of Radical Political Economics, v. 47, n. 4, p. 641-662, 2015.

HILFERDING, R. (1910). O capital financeiro. São Paulo: Nova Cultural, 1985.

HOBSON, J. A. (1906). A evolução do capitalismo moderno. São Paulo: Nova Cultural, 1985.

KALECKI, M. Crescimento e ciclo das economias capitalistas. 2. ed. São Paulo: Hucitec, 1977.

KEYNES, John Maynard (1936). A teoria geral do emprego, do juro e da moeda. São Paulo, SP: Atlas, 1992.

KEYNES, John Maynard. A treatise on money. New York, NY: Macmillan: St. Martin's, 1930. 2v.

LAPAVITSAS, C. Financialised capitalism: crisis and financial expropriation. Historical Materialism, v. 17, p. 114-148, 2009.

LAPAVITSAS, C. Theorizing financialization. Work, Employment and Society, v. 25, n. 4, p. 611-626, 2011.

LENIN, Vladimir Ilitch (1917). Imperialismo, estágio superior do capitalismo: (ensaio popular). São Paulo, SP: Expressão Popular, 2012.

MARX, K. (1894). O capital. São Paulo: Editora Boitempo, 2017.

MINSKY, H. P. The financial instability hypothesis: an interpretation of Keynes and an alternative to "standard" theory. Challenge, v. 20, n. 1, p. 20-27, 1977.

MINSKY, H. P. Schumpeter: finance and evolution. Hyman P. Minsky Archive. Paper 314. Disponível em: http://digitalcommons.bard.edu/hm_archive/3141988.

MINSKY, H. P. The financial instability hypothesis. The Jerome Levy Economics Institute, 1992. (Working Paper, n. 74).

MINSKY, H. P. Finance and stability: the limits of capitalism. Levy Economics Institute, 1993. (Working Paper, n. 93). 
Ricardo Carneiro

PALLUDETO, A. W. A. Os derivativos na literatura marxista: uma crítica. Campinas: Unicamp. Instituto de Economia, maio 2017. (Texto para Discussão, n. 297).

SCHUMPETER, J. A. (1934). Teoria do desenvolvimento econômico: uma investigação sobre lucros, capital, crédito, juro e o ciclo econômico. São Paulo: Abril Cultural, 1982.

VAN der ZWAN, N. Making sense of financialization. Socio-Economic Review, v. 12, n. 1, p. 99-129, 2014. 